\title{
Brief Hyperoxia Increases Mitochondrial Oxidation and Increases Phosphodiesterase 5 Activity in Fetal Pulmonary Artery Smooth Muscle Cells
}

\author{
Kathryn N. Farrow, Keng Jin Lee, Marta Perez,, Jacqueline M. Schriewer, Stephen Wedgwood, \\ Satyan Lakshminrusimha, ${ }^{2}$ Cody L. Smith, Robin H. Steinhorn, and Paul T. Schumacker ${ }^{1}$
}

\begin{abstract}
Aims: Oxygen is a pulmonary vasodilator, but data suggest high $\mathrm{O}_{2}$ concentrations impede that response. We previously reported $24 \mathrm{~h}$ of $100 \% \mathrm{O}_{2}$ increased phosphodiesterase 5 (PDE5) activity in fetal pulmonary artery smooth muscle cells (FPASMC) and in ventilated neonatal lambs. PDE5 degrades cyclic GMP (cGMP) and inhibits nitric oxide (NO)-mediated cGMP-dependent vasorelaxation. We sought to determine the mechanism by which hyperoxia initiates reactive oxygen species (ROS) production and regulates PDE5. Results: Thirty minutes of hyperoxia increased mitochondrial ROS versus normoxia (30.3 $\pm 1.7 \%$ vs. $21.1 \pm 2.8 \%)$, but had no effect on cytosolic ROS, measured by roGFP, a ratiometric protein thiol redox sensor. Hyperoxia increased PDE5 activity $(220 \pm 39 \%)$ and decreased cGMP responsiveness to NO $(37 \pm 17 \%)$. Mitochondrial catalase overexpression attenuated hyperoxia-induced mitochondrial roGFP oxidation, compared to FPASMC infected with empty adenoviral vector $(50 \pm 3 \%$ of control) or mitochondrial superoxide dismutase. MitoTEMPO, mitochondrial catalase, and DT-3, a cGMP-dependent protein kinase I alpha inhibitor, decreased PDE5 activity $(32 \pm 13 \%, 26 \pm 21 \%$, and $63 \pm 10 \%$ of control, respectively), and restored cGMP responsiveness to NO $(147 \pm 16 \%, 172 \pm 29 \%$, and $189 \pm 43 \%$ of control, respectively). C57Bl6 mice exposed to $90 \%-100 \% \mathrm{O}_{2}$ for $45 \mathrm{~min} \pm$ mechanical ventilation had increased PA PDE5 activity (206 $\pm 39 \%$ and $235 \pm 75 \%$, respectively). Innovation: This is the first description that hyperoxia induces ROS in the mitochondrial matrix prior to the cytosol. Our results indicate that short hyperoxia exposures can produce significant changes in critical cellular signaling pathways. Conclusions: These results indicate that mitochondrial matrix oxidant signals generated during hyperoxia, specifically $\mathrm{H}_{2} \mathrm{O}_{2}$, activate PDE5 in a cGMPdependent protein kinase-dependent manner in pulmonary vascular smooth muscle cells. Antioxid. Redox Signal. $17,460-470$.
\end{abstract}

\section{Introduction}

A PPROXIMATELY $10 \%$ OF NEWBORNS require resuscitation after delivery to treat cyanosis, apnea, and/or bradycardia. Current neonatal resuscitation guidelines include early initiation of positive pressure ventilation with $100 \%$ oxygen $\left(\mathrm{O}_{2}\right)$, although these guidelines were recently revised to include blended oxygen $(1,14)$. Oxygen is a pulmonary vasodilator, facilitating the transition from placental to lung respiration. However, optimal therapeutic $\mathrm{O}_{2}$ levels are not well established; excessive $\mathrm{O}_{2}$ tensions induce lung injury, while insufficient levels may not achieve pulmonary vasorelaxation (14). A growing body of evidence suggests that exposure of neonates to supraphysiologic $\mathrm{O}_{2}$ levels may induce

\section{Innovation}

This is the first description that acute hyperoxia induces mitochondrial matrix ROS prior to cytosolic ROS. Our data suggest that redox signals within one subcellular compartment can affect signaling within another subcellular compartment, and provide evidence that even a few minutes of hyperoxia exposure can have a significant impact on the cell signaling milieu. These results are clinically relevant because positive-pressure ventilation with oxygen remains widely used for delivery room resuscitation of infants worldwide, and oxygen is one of the most widely used therapies in all of medicine.

\footnotetext{
${ }^{1}$ Department of Pediatrics, Northwestern University, Chicago, Illinois.
}

${ }^{2}$ Department of Physiology, University of Buffalo, Buffalo, New York. 
long-lasting cellular dysfunction (6, 9, 24, 40). Mechanistic insights are needed to avoid these events and their long-term consequences. An understanding of the critical threshold for $\mathrm{O}_{2}$ exposure would permit judicious use of supplemental $\mathrm{O}_{2}$ in facilitating the normal postnatal pulmonary vascular transition, while avoiding short-term hyperoxic dysfunction and long-term developmental defects.

In utero, pulmonary arteries (PA) are constricted, allowing only $10 \%$ of the cardiac output to circulate through the fetal pulmonary vascular bed. Multiple pathways contribute to the regulation of pulmonary vascular tone in the perinatal period. In particular, increases in endothelial nitric oxide synthase (eNOS) expression, endogenous nitric oxide (NO) production, and soluble guanylate cyclase (sGC) expression at birth contribute to increased cyclic GMP (cGMP) and relaxation of pulmonary vascular tone $(2,3,7,8)$. Phosphodiesterase 5 (PDE5) down-regulates endogenous NO signaling by hydrolyzing cGMP. PDE5 expression normally decreases after birth, further contributing to an increase in cGMP $(6,12)$. Previous studies demonstrate that ventilation of newborn sheep with persistent pulmonary hypertension of the newborn (PPHN) with $100 \% \mathrm{O}_{2}$ for $24 \mathrm{~h}$ increases contractile responses to norepinephrine, but these changes can be prevented by pretreatment with a single dose of an antioxidant, recombinant human superoxide dismutase (rhSOD) or catalase $(18,37)$. Additionally, studies in healthy newborn lambs demonstrate that $30 \mathrm{~min}$ of resuscitation with $100 \% \mathrm{O}_{2}$ attenuates the vasorelaxation response to exogenous $\mathrm{NO}$, suggesting that the NOsGC-cGMP-PDE5 signaling pathway is impaired (17). We reported that exposure of primary FPASMC to $95 \% \mathrm{O}_{2}$ for $24 \mathrm{~h}$ decreases cGMP responsiveness to exogenous $\mathrm{NO}$ and in- creases PDE5 activity and expression (6). Similarly, ventilation of newborn sheep with $100 \% \mathrm{O}_{2}$ for $24 \mathrm{~h}$ increases PDE5 activity and expression and decreases cGMP in resistance PA $(6,7)$. However, we do not understand the mechanism by which hyperoxia regulates PDE5 in the PASMC, and there is no information about the critical threshold or duration of $\mathrm{O}_{2}$ exposure necessary to activate PDE5 and inhibit cGMP signaling. The present study sought to determine the mechanism by which hyperoxia increases PDE5 activity and decreases the cGMP response to exogenous NO in FPASMC.

\section{Results}

\section{Brief hyperoxia exposure increases FPASMC PDE5 activity}

We previously demonstrated that $24 \mathrm{~h}$ of $95 \%-100 \% \mathrm{O}_{2}$ increases PDE5 protein expression and activity in isolated FPASMC and resistance PA from mechanically ventilated neonatal sheep (6). However, the effects of shorter $\mathrm{O}_{2}$ durations on PDE5 were not evaluated. Figure 1 illustrates that $95 \% \mathrm{O}_{2} / 5 \% \mathrm{CO}_{2}$ for 30 min does not affect PDE5 protein expression, but does increase PDE5 activity relative to normoxic $\left(21 \% \mathrm{O}_{2} / 5 \% \mathrm{CO}_{2}\right)$ FPASMC within 20 min after exposure (Fig. 1 and Supplementary Fig. S1A; Supplementary Data are available online at www.liebertonline.com/ars). Similarly, exposure to $75 \% \mathrm{O}_{2} / 5 \% \mathrm{CO}_{2}$ is sufficient to induce PDE5 activity within $30 \mathrm{~min}$ (Supplementary Fig. S1B). Because 30 min seemed too short an interval to detect changes in protein expression, we examined the effects of $95 \% \mathrm{O}_{2} / 5 \%$ $\mathrm{CO}_{2}$ after $4 \mathrm{~h}$ and found significant induction of both PDE5 protein expression and activity (Supplementary Fig. S2).
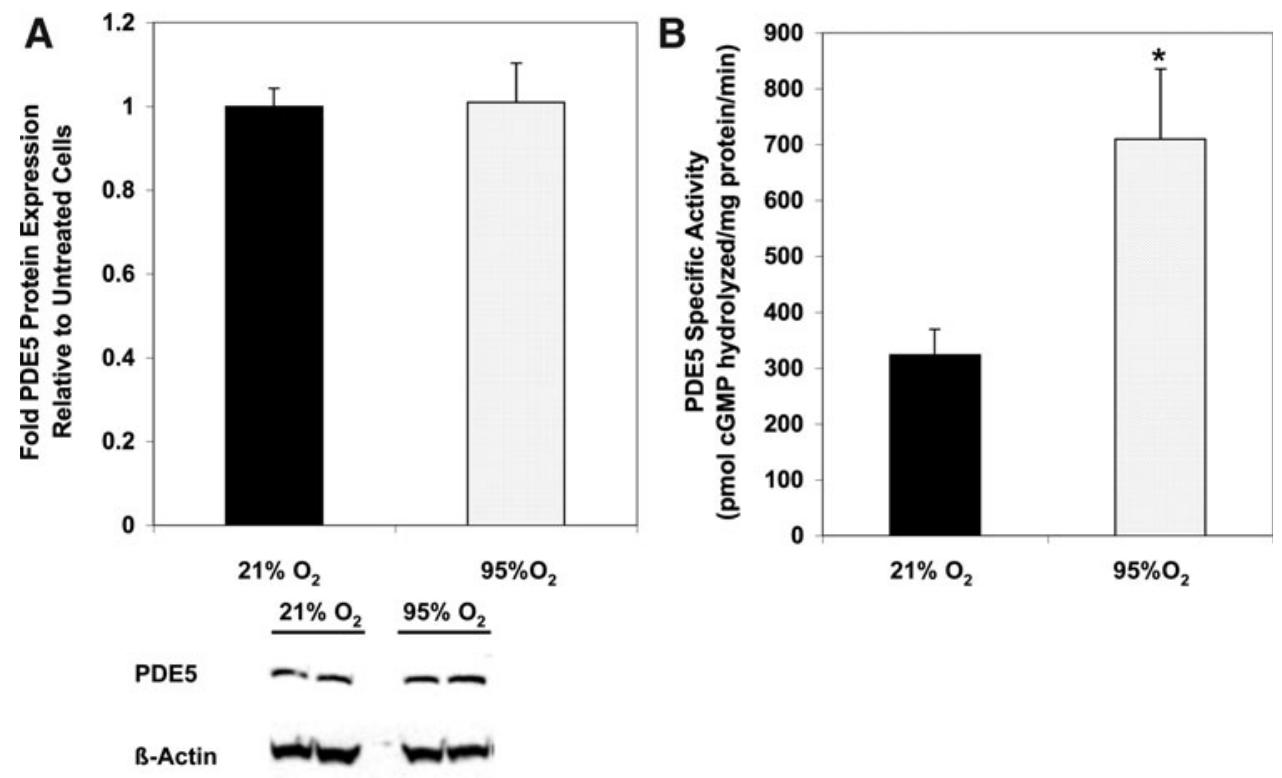

FIG. 1. Thirty minutes of $95 \% \mathrm{O}_{2} / 5 \% \mathrm{CO}_{2}$ increases phosphodiesterase 5 (PDE5) activity but not protein expression. Protein was harvested from fetal pulmonary artery smooth muscle cells (FPASMC) exposed to either $21 \% \mathrm{O}_{2} / 5 \% \mathrm{CO}_{2}$ or $95 \%$ $\mathrm{O}_{2} / 5 \% \mathrm{CO}_{2}$ for $30 \mathrm{~min}$, followed by recovery for $30 \mathrm{~min}$ in $21 \% \mathrm{O}_{2} / 5 \% \mathrm{CO}_{2}$. (A) PDE5 protein expression analyzed by Western blot, normalized for $\beta$-actin $(n=14)$. Data are shown as mean \pm SEM relative to FPASMC in $21 \% \mathrm{O}_{2} / 5 \% \mathrm{CO}_{2}$. A representative Western blot is shown for PDE5 and $\beta$-actin. (B) PDE5-specific cyclic GMP (cGMP) hydrolytic activity was measured using a commercially available colorimetric assay $(n=21$, read in duplicate). Data are shown as mean \pm SEM pmol cGMP hydrolyzed/mg protein/min. ${ }^{*} p<0.05$ vs. FPASMC in $21 \% \mathrm{O}_{2} / 5 \% \mathrm{CO}_{2}$. 


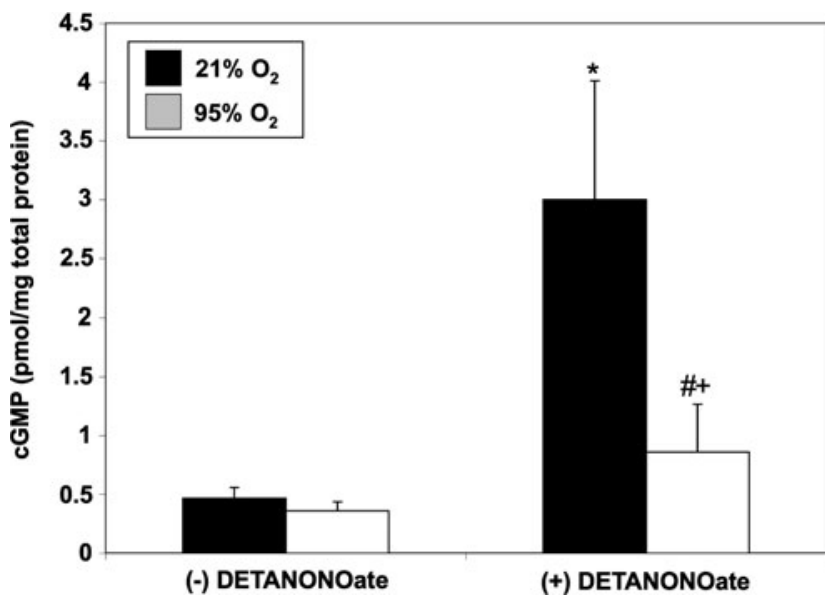

FIG. 2. Thirty minutes of $95 \% \mathrm{O}_{2} / 5 \% \mathrm{CO}_{2}$ blunts cGMP responsiveness to exogenous nitric oxide (NO). FPASMC were exposed to $21 \% \mathrm{O}_{2} / 5 \% \quad \mathrm{CO}_{2}$ or $95 \% \mathrm{O}_{2} / 5 \% \mathrm{CO}_{2} \pm$ DETANONOate $(100 \mu \mathrm{M})$ for $30 \mathrm{~min}$, followed by recovery for $30 \mathrm{~min}$ in $21 \% \mathrm{O}_{2} / 5 \% \mathrm{CO}_{2}$. Cells were harvested and assayed for cGMP by enzyme immunoassay (EIA). cGMP levels were normalized to total protein. Data are shown as mean \pm SEM ( $n=10$, read in duplicate). ${ }^{*} p<0.05$ vs. untreated FPASMC in $21 \% \mathrm{O}_{2} / 5 \% \mathrm{CO}_{2} ;{ }^{\#} p<0.05$ vs. untreated FPASMC in $95 \% \mathrm{O}_{2} /$ $5 \% \mathrm{CO}_{2} ;{ }^{+} p<0.05$ vs. NO-treated PASMC in $21 \% \mathrm{O}_{2} / 5 \% \mathrm{CO}_{2}$.

\section{Brief hyperoxia decreases cGMP response to exogenous NO}

PDE5 hydrolyzes cGMP and down-regulates NO signaling. We sought to determine if hyperoxia-mediated PDE5 induction would attenuate the cGMP response to an exogenous $\mathrm{NO}$ stimulus in FPASMC. After $30 \mathrm{~min}$ of exposure to $95 \% \mathrm{O}_{2} / 5 \%$ $\mathrm{CO}_{2}$, the cGMP response to the NO donor, DETANONOate, was significantly blunted as compared to normoxic FPASMC (Fig. 2). Exposure to $95 \% \mathrm{O}_{2} / 5 \% \mathrm{CO}_{2}$ for $4 \mathrm{~h}$ similarly blunted the cGMP response to DETANONOate (Supplementary Fig. S3). The cGMP response to NO depends on sGC and PDE5 activities. Thus, we sought to determine if hyperoxia-induced PDE5 activity was solely responsible for this blunted cGMP response to NO. Pretreatment with sildenafil $(100 \mathrm{nM})$ significantly decreased PDE5 activity in hyperoxia-exposed FPASMC relative to untreated FPASMC (Fig. 3A) and restored normal cGMP response to exogenous NO (Fig. 3B). These findings indicate that a significant component of the attenuated NO response after brief hyperoxia is due to increased PDE5 activity. Of note, sildenafil augments the cGMP response to exogenous $\mathrm{NO}$ in normoxia as well, likely due to the fact that PDE5 largely regulates the NO-stimulated cGMP pool, not basal cGMP (6).

\section{Brief hyperoxia increases mitochondrial, but not cytosolic oxidation}

We previously demonstrated that FPASMC exposure to 95\% $\mathrm{O}_{2} / 5 \% \mathrm{CO}_{2}$ for $24 \mathrm{~h}$ increases reactive oxygen species (ROS) in the cytosol and the mitochondrial matrix $(6,9)$. We sought to determine the temporal relationship between the increase in ROS in one compartment and the other. Oxidation within subcellular compartments was assessed using the ratiometric thiol sensor, roGFP. Under normoxic conditions, the mitochondrial matrix exhibited a more oxidized state compared with the cytosol (Fig. 4A). During exposure to $95 \% \mathrm{O}_{2} / 5 \% \mathrm{CO}_{2}$, no change in the cytosolic oxidative state was detected within $30 \mathrm{~min}$. In contrast, oxidation within the mitochondrial matrix increased significantly within $15 \mathrm{~min}$, reaching maximal oxidation within $30 \mathrm{~min}$. Upon return to $21 \% \mathrm{O}_{2} / 5 \% \mathrm{CO}_{2}$, matrix oxidation decreased progressively, reaching baseline levels within $16 \mathrm{~min}$. Similarly, no change in cytosolic oxidative state was observed after $4 \mathrm{~h}$ under $95 \% \mathrm{O}_{2} / 5 \% \mathrm{CO}_{2}$, whereas the mitochondrial matrix oxidant status increased compared with normoxia (Supplementary Fig. S4). We sought to determine whether increased mitochondrial oxidation was due to superoxide or $\mathrm{H}_{2} \mathrm{O}_{2}$. We demonstrated no change in fluorescence
A

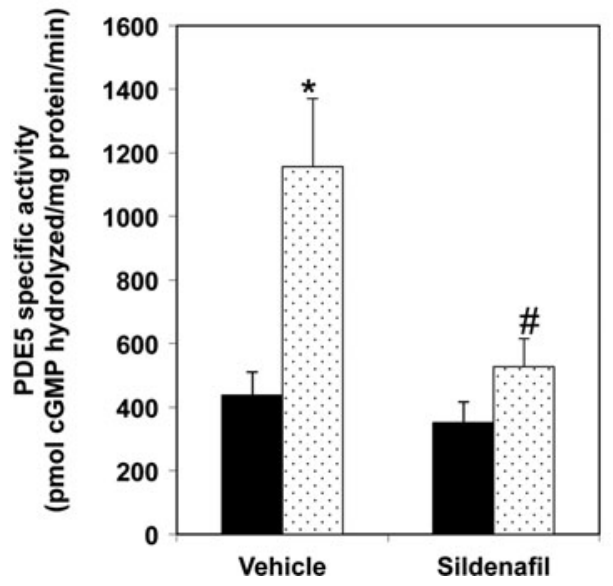

B

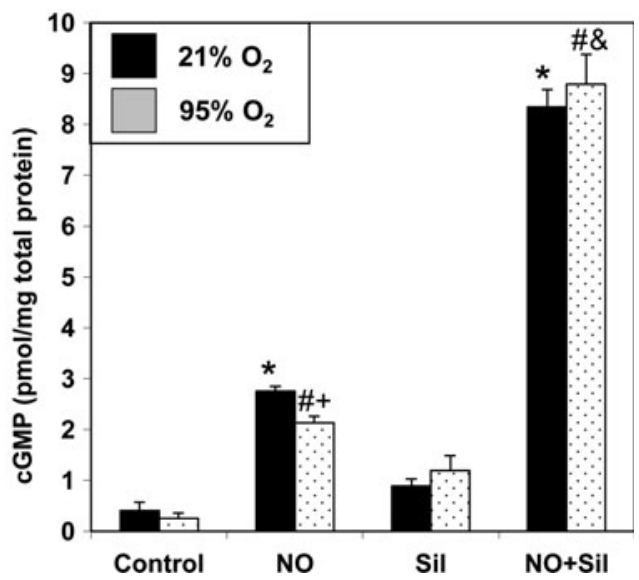

FIG. 3. Sildenafil blocks hyperoxia-induced PDE5 activity and restores cGMP responsiveness to exogenous NO. FPASMC were exposed to $21 \% \mathrm{O}_{2} / 5 \% \mathrm{CO}_{2}$ or $95 \% \mathrm{O}_{2} / 5 \% \mathrm{CO}_{2}$ for $30 \mathrm{~min} \pm$ sildenafil (Sil, 100 nM) or vehicle (dimethylsulfoxide [DMSO]) and \pm DETANONOate $(\mathrm{NO}, 100 \mu \mathrm{M})$, followed by recovery for $30 \mathrm{~min}$ in $21 \% \mathrm{O}_{2} / 5 \% \mathrm{CO}_{2}$. (A) PDE5-specific cGMP hydrolytic activity was measured using a commercially available colorimetric assay ( $n=9$, read in duplicate). Data are shown as mean \pm SEM pmol cGMP hydrolyzed/mg protein $/ \mathrm{min}$. (B) Cells were assayed for cGMP by EIA, and cGMP was normalized to total protein. Data are shown as mean \pm SEM ( $n=3$, read in duplicate). ${ }^{*} p<0.05$ vs. untreated FPASMC in $21 \% \mathrm{O}_{2} / 5 \% \mathrm{CO}_{2} ;{ }^{\#} p<0.05$ vs. untreated FPASMC in $95 \% \mathrm{O}_{2} / 5 \% \mathrm{CO}_{2} ;{ }^{+} p<0.05$ vs. NO-treated PASMC in $21 \% \mathrm{O}_{2} / 5 \% \mathrm{CO}_{2}, a_{p}<0.05$ vs. NO-treated PASMC in $95 \% \mathrm{O}_{2} / 5 \% \mathrm{CO}_{2}$. 

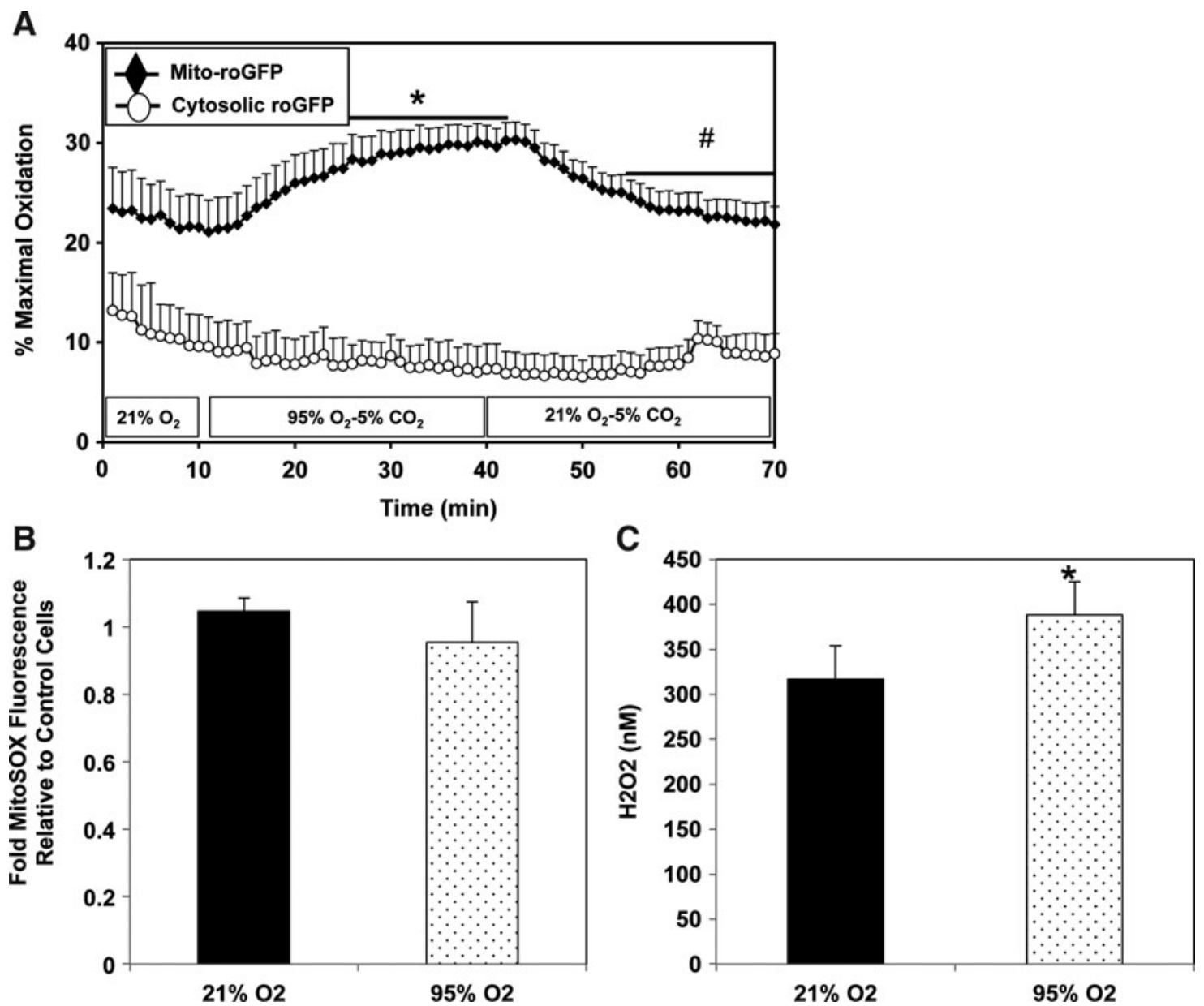

FIG. 4. Exposure to hyperoxia induces mitochondrial matrix $\mathrm{H}_{2} \mathrm{O}_{2}$ in FPASMC. (A) The redox sensor roGFP was used to assess oxidant levels in cytosol and mitochondrial matrix. Surface-exposed cysteine residues are sensitive to the local redox environment. After obtaining ratiometric measurements of roGFP, the sensor was calibrated by maximally reducing it with dithiothreitol (DTT, $1 \mathrm{mM}$ ) and maximally oxidizing it with t-butyl hydroperoxide (TBH, $1 \mathrm{mM}$ ) to yield percent oxidation. FPASMC were plated on collagen-coated cover slips and were exposed in a flow-through chamber on an epifluorescence microscope to $95 \% \mathrm{O}_{2} / 5 \% \mathrm{CO}_{2}$ for $30 \mathrm{~min}$, followed by a 30-min recovery period in $21 \% \mathrm{O}_{2} / 5 \% \mathrm{CO}_{2}$. Data shown are from 19 cells from four coverslips for mito-roGFP and 7 cells from five coverslips for cytosolic roGFP. ${ }^{*} p<0.05$ vs. FPASMC baseline oxidation in $21 \% \mathrm{O}_{2} / 5 \% \mathrm{CO}_{2} ;{ }^{*} p<0.05$ vs. FPASMC maximal oxidation in $95 \% \mathrm{O}_{2} / 5 \% \mathrm{CO}_{2}$. (B) FPASMC were loaded with MitoSOX, a fluorescent mitochondrially targeted superoxide sensor, prior to $30 \mathrm{~min}$ of exposure to $95 \% \mathrm{O}_{2} / 5 \% \mathrm{CO}_{2}$ ( $n=10$, measured in duplicate). (C) FPASMC were exposed to $95 \% \mathrm{O}_{2} / 5 \% \mathrm{CO}_{2}$ for $30 \mathrm{~min}$, and intracellular $\mathrm{H}_{2} \mathrm{O}_{2}$ was quantified with Amplex Red fluorescence $\left(n=8,{ }^{*} p<0.05\right.$ vs. FPASMC in $\left.21 \% \mathrm{O}_{2} / 5 \% \mathrm{CO}_{2}\right)$.

of MitoSOX, a mitochondrially targeted superoxide sensor (Fig. 4B). We did detect increased intracellular $\mathrm{H}_{2} \mathrm{O}_{2}$ by Amplex Red fluorescence (Fig. 4C) but could not localize the source to any specific subcellular compartment.

To determine if overexpression of antioxidant enzymes would abrogate this hyperoxia-induced mitochondrial oxidative response, we overexpressed MnSOD and mito-catalase using recombinant adenoviruses (Supplementary Figs. S5 and S6) (35). Interestingly, MnSOD overexpression did not abrogate, but instead enhanced the hyperoxia-induced oxidation of mito-roGFP (Fig. 5). However, mito-catalase expression significantly blunted the response, as compared to cells treated with empty adenovirus (Fig. 5).

\section{MitoTEMPO and mito-catalase block hyperoxia-induced increases in PDE5 activity}

To determine if mitochondrial oxidation directly increased PDE5 activity, we utilized the mitochondrially targeted antioxidant, MitoTEMPO, which scavenges mitochondrial superoxide and decreases mitochondrial $\mathrm{H}_{2} \mathrm{O}_{2}$ (5). Pretreatment with MitoTEMPO significantly blunted the hyperoxia-mediated increase in PDE5 activity (Fig. 6A) and significantly improved cGMP accumulation to exogenous NO in comparison to vehicle-treated FPASMC (Fig. 6B).

We next determined if overexpression of antioxidant enzymes would block hyperoxia-induced increases in PDE5 activity and restore cGMP responsiveness to exogenous NO. MnSOD overexpression did not abolish hyperoxia-induced increases in PDE5 activity (Fig. 7A), nor did it improve cGMP response to $\mathrm{NO}$ in hyperoxia-exposed FPASMC (Fig. 7B). Surprisingly, MnSOD overexpression in normoxic FPASMC led to a small but significant decrease in the cGMP response to exogenous NO (Fig. 7B). However, mito-catalase overexpression in FPASMC in $95 \% \mathrm{O}_{2} / 5 \% \mathrm{CO}_{2}$ blocked the increase in PDE5 activity compared to FPASMC infected with 


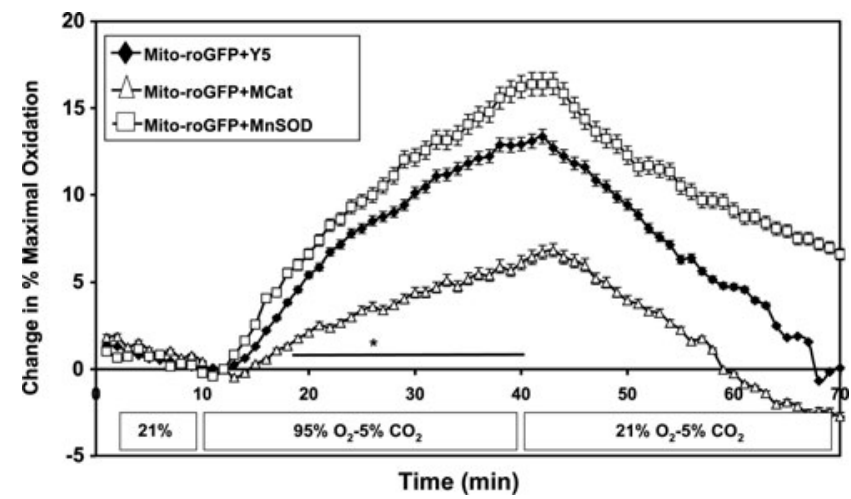

FIG. 5. Mito-catalase, but not MnSOD, blocks hyperoxiainduced increases in mitochondrial matrix oxidation in FPASMC. FPASMC were plated on collagen-coated cover slips, infected with adenoviral mito-catalase, adenoviral MnSOD, or empty virus (Y5) $48 \mathrm{~h}$ prior to hyperoxic exposure, and studied in a flow-through chamber on an epifluorescence microscope during $95 \% \mathrm{O}_{2} / 5 \% \mathrm{CO}_{2}$ for $30 \mathrm{~min}$, followed by a $30-\mathrm{min}$ recovery in $21 \% \mathrm{O}_{2} / 5 \% \mathrm{CO}_{2}$. Data shown are from 100 cells from 10 coverslips for mitoroGFP + Y5, 22 cells from four coverslips for mito-roGFP + mito-catalase (MCat), and 45 cells from five coverslips for mito-roGFP + MnSOD. ${ }^{*} p<0.05$ for mito-roGFP + mitocatalase vs. mito-roGFP $+\mathrm{Y} 5$.

empty virus (Fig. 7C), and improved cGMP response to exogenous NO (Fig. 7D).

Hyperoxia augments PDE5 activity in a cGMP-dependent protein kinase I alpha-dependent manner

Cyclic GMP-dependent protein kinase (PKG)-mediated phosphorylation has been reported to increase PDE5 activity, and we have shown that $24 \mathrm{~h}$ of hyperoxia increases PDE5 phosphorylation $(6,25)$. In the present study, we demonstrate increased PDE5 phosphorylation at the previously charac- terized PKG phosphorylation site after $30 \mathrm{~min}$ of hyperoxia (Fig. 8A). DT-3, a peptide inhibitor of cGMP-dependent protein kinase I alpha (PKGI $\alpha$ ), significantly blunted the hyperoxia-mediated increase in PDE5 activity (Fig. 8B). Likewise, DT-3 significantly improved the cGMP response to exogenous NO in hyperoxia-exposed FPASMC in comparison to vehicletreated FPASMC (Fig. 8C).

\section{Hyperoxia increases PDE5 activity in small $P A$ in adult mice}

To determine the relevance of our findings in a whole animal model, we exposed C57Bl6 young adult male mice to hyperoxia both with and without mechanical ventilation. Both mechanical ventilation with $100 \% \mathrm{O}_{2}$ and exposure to $90 \% \mathrm{O}_{2}$ without mechanical ventilation for $45 \mathrm{~min}$ led to a similar increase in small PA PDE5 activity (Fig. 9A), suggesting that hyperoxia, not mechanical ventilation, is directly responsible for increased PA PDE5 activity. While isolated PA consist of multiple cell types, we also confirmed that hyperoxia exposure for $30 \mathrm{~min}$ increased PDE5 activity in isolated adult mouse PASMC (Supplementary Fig. S7). Similarly, mice that were mechanically ventilated with $100 \% \mathrm{O}_{2}$ had decreased total lung cGMP relative to room air nonventilated controls (Fig. 9B).

\section{Discussion}

Using a ratiometric sensor to assess thiol protein oxidation status in subcellular compartments of FPASMC, we find that hyperoxia induces a selective increase in mitochondrial matrix oxidation within $15 \mathrm{~min}$; this response is attenuated by catalase overexpression targeted to the same compartment. Additional studies with Amplex Red demonstrate an increase in intracellular $\mathrm{H}_{2} \mathrm{O}_{2}$ with hyperoxia exposure, but these studies cannot localize the $\mathrm{H}_{2} \mathrm{O}_{2}$ within a specific subcellular compartment. Taken together, these findings indicate that hyperoxia acutely increases the generation of $\mathrm{H}_{2} \mathrm{O}_{2}$ in the mitochondrial matrix compartment. Over a similar time
A

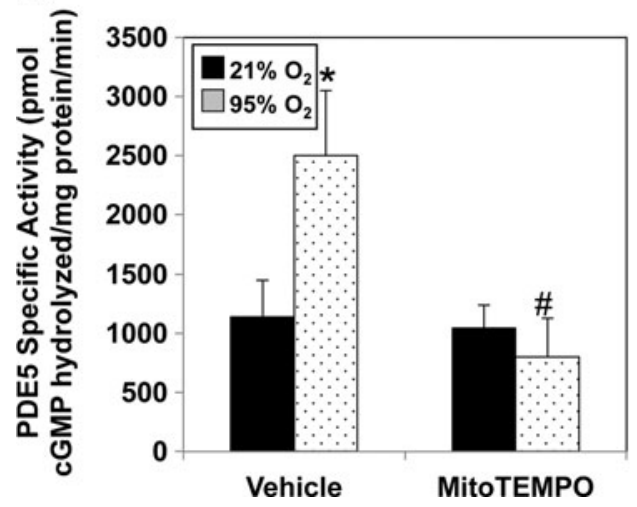

B

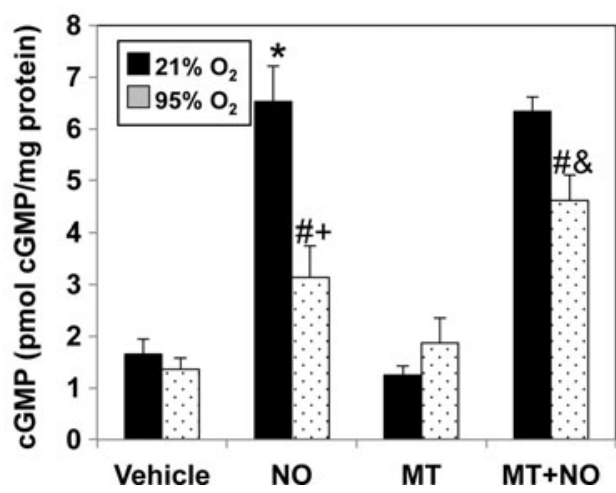

FIG. 6. MitoTEMPO, a mitochondrially targeted antioxidant, blocks hyperoxia-induced PDE5 activity and restores cGMP responsiveness to exogenous NO. FPASMC were exposed to $21 \% \mathrm{O}_{2} / 5 \% \mathrm{CO}_{2}$ or $95 \% \mathrm{O}_{2} / 5 \% \mathrm{CO}_{2}$ for $30 \mathrm{~min} \pm$ MitoTEMPO $(25 \mathrm{nM})$ or vehicle (DMSO), followed by recovery for $30 \mathrm{~min}$ in $21 \% \mathrm{O}_{2} / 5 \% \mathrm{CO}_{2}$. (A) PDE5-specific cGMP hydrolytic activity in the absence or presence of MitoTEMPO is measured using a commercially available colorimetric assay $(n=7$, read in duplicate). Data are shown as mean \pm SEM pmol cGMP hydrolyzed/mg protein/min. (B) FPASMC \pm MitoTEMPO $(\mathrm{MT}) \pm$ DETANONOate $(100 \mu \mathrm{M}, \mathrm{NO})$ were assayed for cGMP by EIA, and cGMP was normalized to total protein. Data are shown as mean \pm SEM $\left(n=5\right.$, read in duplicate). ${ }^{*} p<0.05$ vs. untreated $\mathrm{FPASMC}$ in $21 \% \mathrm{O}_{2} / 5 \% \mathrm{CO}_{2}$; ${ }^{\#} p<0.05$ vs. untreated FPASMC in $95 \% \mathrm{O}_{2} / 5 \% \mathrm{CO}_{2} ;{ }^{+} p<0.05$ vs. NO-treated PASMC in $21 \% \mathrm{O}_{2} / 5 \% \mathrm{CO}_{2},{ }^{*} p<0.05$ vs. NOtreated PASMC in $95 \% \mathrm{O}_{2} / 5 \% \mathrm{CO}_{2}$. 
A

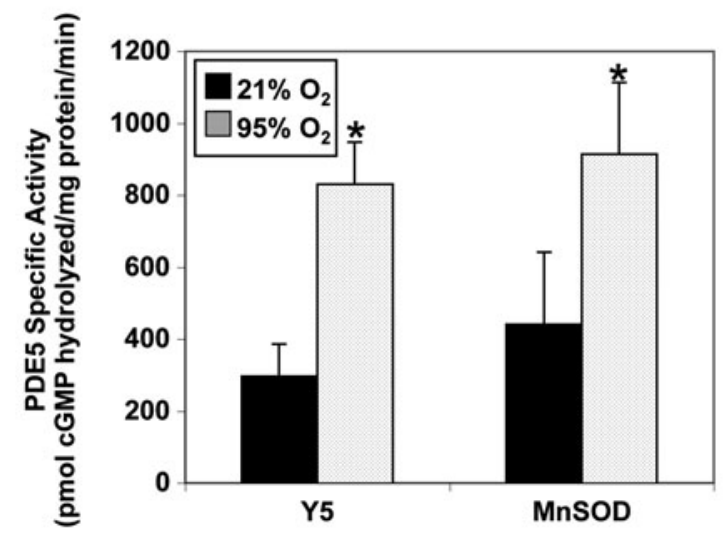

\section{C}

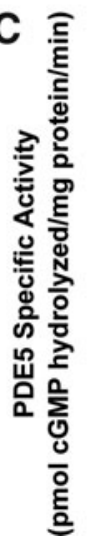

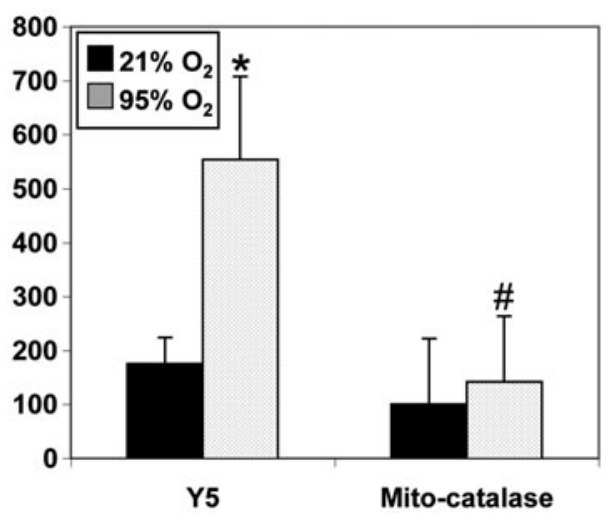

B

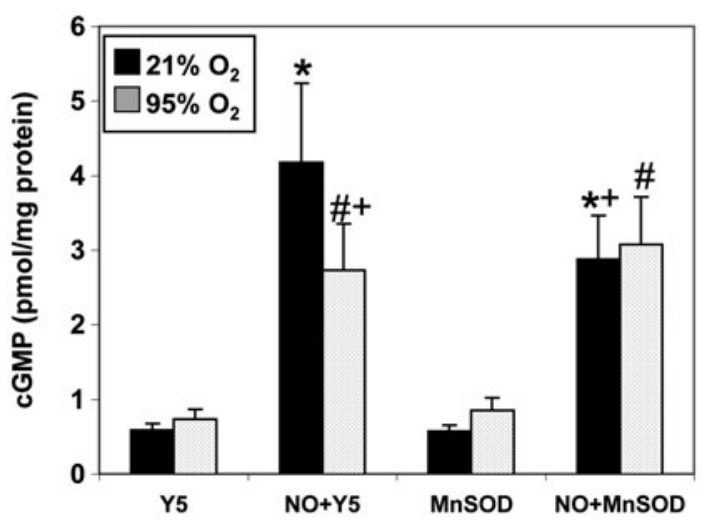

D

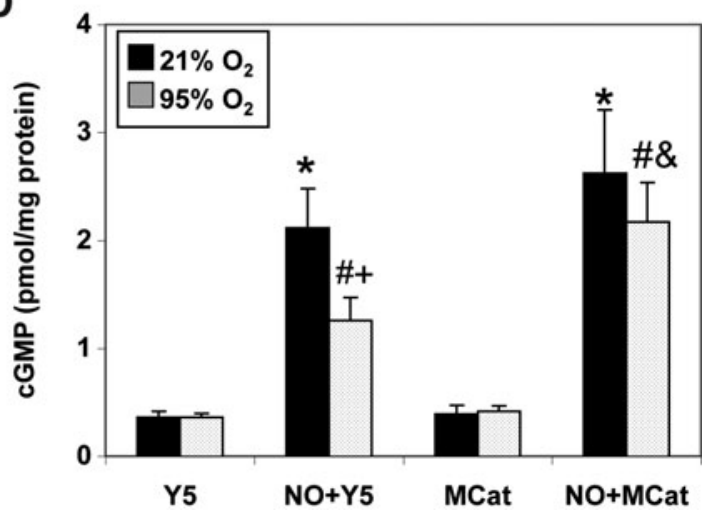

FIG. 7. Mito-catalase, but not MnSOD, blocks hyperoxia-induced PDE5 activity and restores cGMP responsiveness to exogenous NO. FPASMC were exposed to $21 \% \mathrm{O}_{2} / 5 \% \mathrm{CO}_{2}$ or $95 \% \mathrm{O}_{2} / 5 \% \mathrm{CO}_{2}$ for $30 \mathrm{~min} \pm \mathrm{MnSOD}$, mito-catalase, or empty adenoviral vector, followed by recovery for $30 \mathrm{~min}$ in $21 \% \mathrm{O}_{2} / 5 \% \mathrm{CO}_{2}$. (A) PDE5-specific cGMP hydrolytic activity in the absence or presence of MnSOD overexpression is measured using a commercially available colorimetric assay $(n=6$, read in duplicate). (B) FPASMC \pm MnSOD overexpression \pm DETANONOate $(100 \mu \mathrm{M}, \mathrm{NO})$ were assayed for cGMP by EIA, and cGMP was normalized to total protein $(n=13$, read in duplicate). (C) PDE5-specific cGMP hydrolytic activity in the absence or presence of mito-catalase overexpression is measured as in $\mathbf{A}(n=9$, read in duplicate). (D) FPASMC \pm mito-catalase overexpression \pm DETANONOate were assayed for cGMP and normalized to total protein as in B ( $n=18$, read in duplicate). Data are shown as mean \pm SEM. ${ }^{*} p<0.05$ vs. untreated FPASMC in $21 \% \mathrm{O}_{2} / 5 \% \mathrm{CO}_{2} ;{ }^{\#} p<0.05$ vs. untreated FPASMC in $95 \% \mathrm{O}_{2} /$ $5 \% \mathrm{CO}_{2} ;{ }^{+} p<0.05$ vs. NO-treated PASMC in $21 \% \mathrm{O}_{2} / 5 \% \mathrm{CO}_{2},{ }^{\&} p<0.05$ vs. NO-treated $\mathrm{PASMC}$ in $95 \% \mathrm{O}_{2} / 5 \% \mathrm{CO}_{2}$.

interval, no change in the cytosolic oxidation state was observed, suggesting that the matrix is the compartment where oxidants are first generated in response to hyperoxia. This finding contrasts recent reports utilizing similar roGFP tools showing that acute hypoxia increases cytosolic but not mitochondrial oxidant status in rat PASMC (36). Collectively, these findings indicate that hyperoxia and hypoxia generate ROS by distinct mechanisms in subcellular compartments, which explains why they evoke different signaling responses in the pulmonary circulation.

The present study also shows that supraphysiologic oxygen increases PDE5 activity in as little as $20 \mathrm{~min}$. Hyperoxia also decreases the cGMP response to exogenous NO, which can be prevented by sildenafil, a PDE5-specific inhibitor. Thus, the hyperoxia-mediated decrease in cGMP response to exogenous $\mathrm{NO}$ is due to increased PDE5 activity. Additionally, sildenafil may further impact cGMP response to exogenous NO by inhibiting PDE1, which is important in adult pulmonary hypertension, or by decreasing ROS through other mechanisms $(10,13,29,31)$. A mitochondrially targeted antioxidant, MitoTEMPO, attenuated the hyperoxiainduced increase in PDE5 activity and restored cGMP responsiveness to NO, but MitoTEMPO can decrease both superoxide and $\mathrm{H}_{2} \mathrm{O}_{2}$ in mitochondria, and thus does not identify a specific oxidant (5). Mitochondrial expression of catalase, but not MnSOD, attenuated hyperoxia-induced PDE5 activity and restored cGMP responsiveness to NO, implicating $\mathrm{H}_{2} \mathrm{O}_{2}$ as the critical oxidant for impacting PDE5. Finally, DT-3, a PKGI $\alpha$ inhibitor, prevented the hyperoxiainduced increase in PDE5 activity and restored cGMP responsiveness to NO. Thus, mitochondrial matrix ROS, specifically $\mathrm{H}_{2} \mathrm{O}_{2}$, is responsible for the induction of PDE5 activity through a PKGI $\alpha$-dependent mechanism (Fig. 10).

The increase in NO and cGMP and decrease in PDE5 activity are important for the normal pulmonary vascular transition after birth $(2,6,12)$. In healthy near-term sheep as well as sheep with PPHN, mechanical ventilation with 100\% $\mathrm{O}_{2}$ for $24 \mathrm{~h}$ increased ROS, increased PDE5 protein expression and activity, and decreased steady-state cGMP levels in the resistance PA (6-8). In PPHN lambs, treatment with an 
A
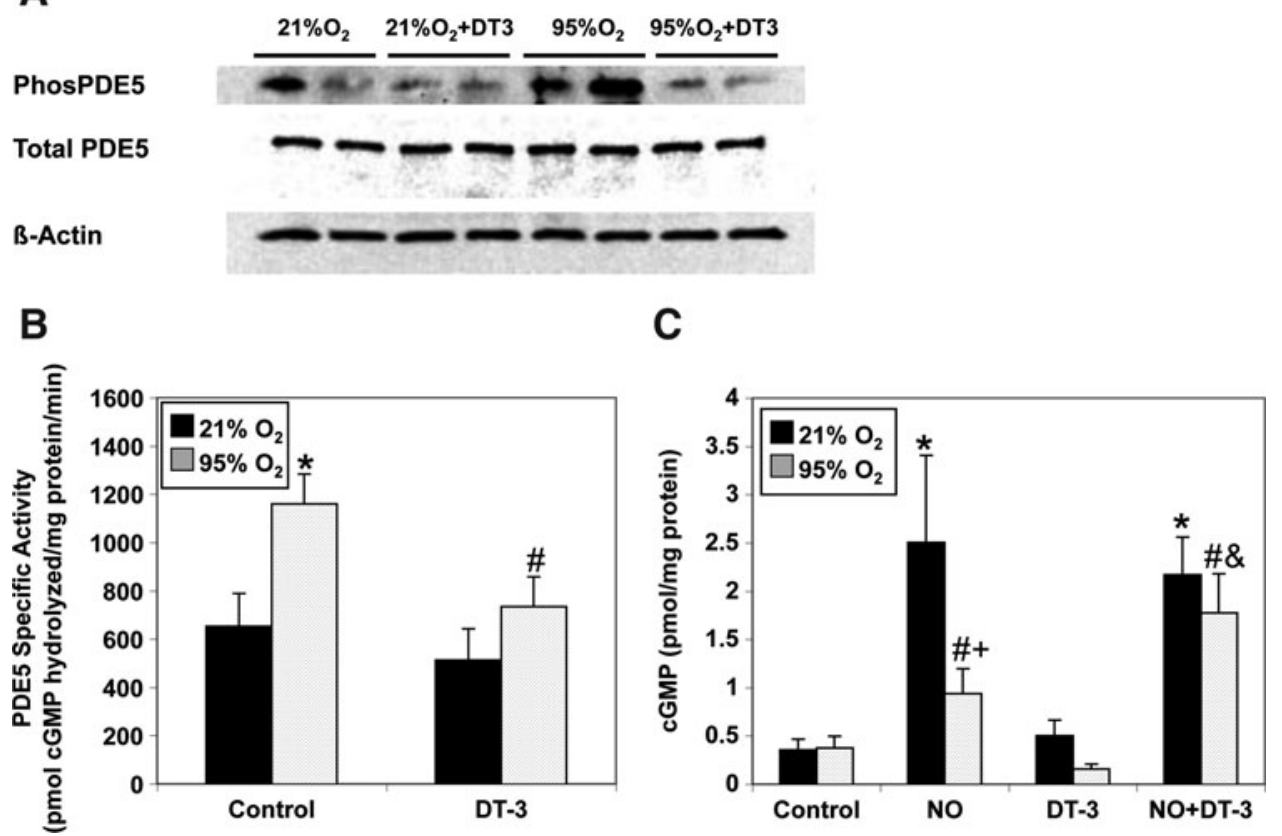

FIG. 8. DT-3, a PKGI $\alpha$ inhibitor, blocks hyperoxia-induced PDE5 activity and restores cGMP responsiveness to exogenous NO. FPASMC were exposed to $21 \% \mathrm{O}_{2} / 5 \% \mathrm{CO}_{2}$ or $95 \% \mathrm{O}_{2} / 5 \% \mathrm{CO}_{2}$ for $30 \mathrm{~min} \pm \mathrm{DT}-3$ (15 $\mu \mathrm{M}$ ) or vehicle (DMSO), followed by recovery for $30 \mathrm{~min}$ in $21 \% \mathrm{O}_{2} / 5 \% \mathrm{CO}_{2}$. (A) A representative Western blot is shown for PhosphoPDE5, PDE5, and $\beta$-actin. (B) PDE5-specific cGMP hydrolytic activity in the absence or presence of DT-3 is measured using a commercially available colorimetric assay ( $n=16$, read in duplicate). Data are shown as mean \pm SEM pmol cGMP hydrolyzed/mg protein/ min. (C) FPASMC \pm DT-3 \pm DETANONOate $(100 \mu \mathrm{M}, \mathrm{NO})$ were assayed for cGMP by EIA, and cGMP was normalized to total protein. Data are shown as mean \pm SEM $\left(n=8\right.$, read in duplicate). ${ }^{*} p<0.05$ vs. untreated $\mathrm{FPASMC}$ in $21 \% \mathrm{O}_{2} / 5 \% \mathrm{CO}_{2}$; ${ }^{\#} p<0.05$ vs. untreated FPASMC in $95 \% \mathrm{O}_{2} / 5 \% \mathrm{CO}_{2} ;{ }^{+} p<0.05$ vs. NO-treated PASMC in $21 \% \mathrm{O}_{2} / 5 \% \mathrm{CO}_{2},{ }^{*} p<0.05$ vs. NOtreated PASMC in $95 \% \mathrm{O}_{2} / 5 \% \mathrm{CO}_{2}$.

antioxidant, either rhSOD or catalase, significantly decreased PDE5 activity and increased cGMP levels in the resistance PA suggesting that these changes were oxidantmediated $(7,9)$. In isolated FPASMC, exposure to $95 \% \mathrm{O}_{2}$ for $24 \mathrm{~h}$ decreased cGMP responsiveness to exogenous $\mathrm{NO}$ and increased PDE5 expression and activity. These changes were rescued by pretreatment with the chemical antioxidant $\mathrm{N}$ acetyl-cysteine, suggesting that oxygen-mediated regulation of PDE5 is ROS dependent (6). While our previous data suggested that both cytosolic and mitochondrial ROS were increased after $24 \mathrm{~h}$ of hyperoxia, we recently demonstrated that pretreatment of FPASMC with mitochondrially targeted

\section{A}

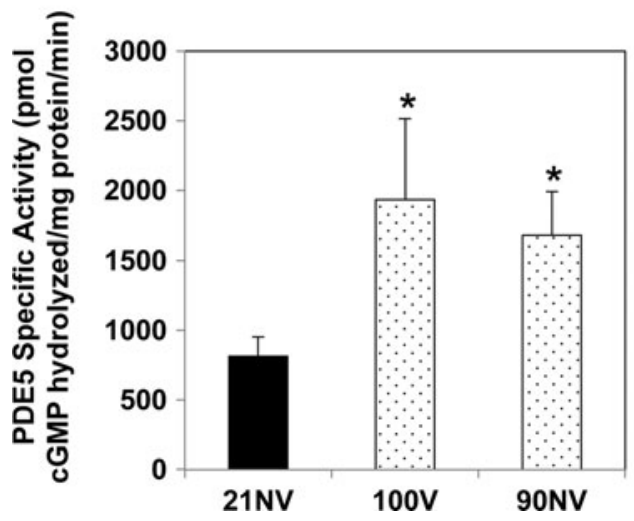

B

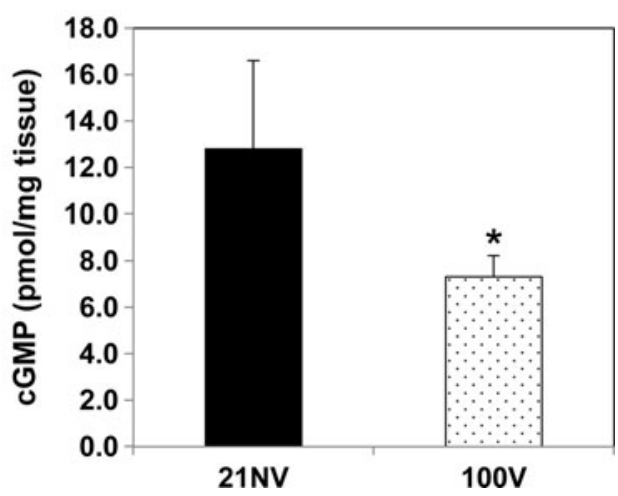

FIG. 9. Hyperoxia exposure increases PDE5 activity in small PA from adult mice. Male C57Bl6 mice were placed into three experimental groups: 1) room air, nonventilated (21NV), 2) mechanically ventilated with $100 \% \mathrm{O}_{2}$ for 45 min $(100 \mathrm{~V})$, and 3) $90 \% \mathrm{O}_{2}$ exposure for $45 \mathrm{~min}$ in an animal hyperoxia chamber (Biospherix; 90NV). (A) PDE5-specific cGMP hydrolytic activity in the small PA is measured using a commercially available colorimetric assay ( $n=5$ per group, read in duplicate). Data are shown as mean \pm SEM pmol cGMP hydrolyzed/mg protein/min. (B) cGMP content of lung tissue was measured via EIA, and cGMP was normalized to milligrams of tissue. Data are shown as mean \pm SEM ( $n=5$, read in duplicate). ${ }^{*} p<0.05$ vs. $21 \mathrm{NV}$ animals. 


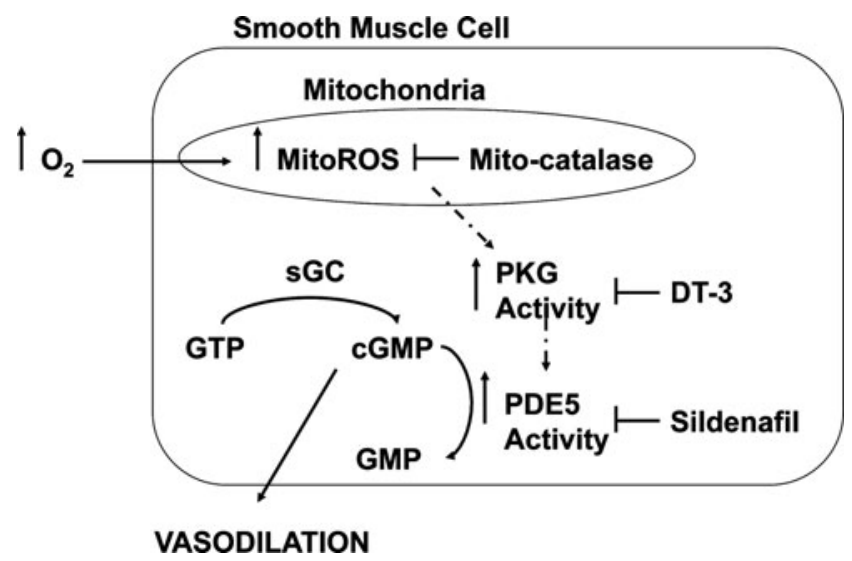

FIG. 10. Model for hyperoxia-induced PDE5 activity in FPASMC. Exposure to hyperoxia leads to increased $\mathrm{H}_{2} \mathrm{O}_{2}$, within the mitochondrial matrix. This increase in mitochondrial $\mathrm{H}_{2} \mathrm{O}_{2}$ increases PDE5 expression and activity in a PKGmediated fashion. The increased PDE5 activity ultimately decreases the amount of cGMP produced in response to NO, leading to impaired NO-mediated vasorelaxation.

catalase (mito-catalase) blocked PDE5 activity induced by $24 \mathrm{~h}$ of $95 \% \mathrm{O}_{2}$, suggesting that hyperoxia-induced changes in PDE5 activity were due to mitochondrial ROS (9). The present study suggests that the increase in mitochondrial $\mathrm{H}_{2} \mathrm{O}_{2}$ precedes changes in cytosolic ROS and that mitochondrial $\mathrm{H}_{2} \mathrm{O}_{2}$ is the key trigger of elevated PDE5 activity.

When animals or cells are exposed to prolonged hyperoxia, responses may involve post-translational modifications to proteins and changes in gene expression. However, many infants are only exposed to hyperoxic gas mixtures briefly, during delivery room resuscitation or due to mild respiratory distress after birth. While $\mathrm{O}_{2}$ is a well-known pulmonary vasodilator, recent animal data indicate that even brief exposure to $100 \% \mathrm{O}_{2}$ may adversely affect pulmonary vascular tone, while activating markers of oxidative stress $(16,17,32)$. In human studies, delivery room resuscitation with $100 \% \mathrm{O}_{2}$ results in lower Apgar scores and a longer time to first cry compared with infants resuscitated with $21 \% \mathrm{O}_{2}(27,28)$. Additionally, 28 days later, infants resuscitated with $100 \% \mathrm{O}_{2}$ show increased oxidative stress markers, including low reduced-to-oxidized glutathione ratios (32). Further, in healthy and PPHN lambs, 30 min of resuscitation with $100 \% \mathrm{O}_{2}$ suppressed pulmonary vascular relaxations to $\mathrm{NO}$, suggesting impairment of NO-sGC-cGMP-PDE5 signaling $(17,19)$.

In the present study, we find that exposure to as little as $20 \mathrm{~min}$ of $95 \% \mathrm{O}_{2}$ is sufficient to induce PDE5 activity in FPASMC. These hyperoxic effects are dose dependent, such that exposure to greater than $50 \% \mathrm{O}_{2}$ was required to induce PDE5 activity (Supplementary Fig. S1). The induction of PDE5 activity mirrors the increase in mitochondrial ROS, and selective targeting of mitochondrial ROS abolishes the PDE5 response. These results suggest that hyperoxia-induced mitochondrial $\mathrm{H}_{2} \mathrm{O}_{2}$ triggers the increase in PDE5 activity, and it is likely that the intermediate signaling event is rapid and induces post-translational modification of PDE5 by activating PKG. It was previously shown that PDE5 expression and activity can be regulated in an ROS-dependent manner, but after exposures of $16 \mathrm{~h}$ to 2 weeks $(6,20,21,23)$. Studies of PDE5 activity in gastric and aortic smooth muscle indicate that PKG phosphorylates and activates PDE5 $(22,25)$. Indeed, both hyperoxia for $24 \mathrm{~h}$ and $30 \mathrm{~min}$ increases PDE5 phosphorylation at the previously characterized PKG phosphorylation site (Fig. 8A) (6). There is increasing evidence that PKG is regulated by cellular redox status, making it a likely candidate as the intermediary between ROS and PDE5 $(4,26,30)$. While oxidant stress can potentially activate PKG by oxidizing cysteine residues in zinc-finger domains of the protein, the mechanism of PKG activation in the present study is perplexing because the oxidant stress occurred in the matrix but was not observed in the cytosol where the PKG acts on PDE5. One possible explanation is that PKG resides on the endoplasmic reticulum membrane near mitochondria, which could allow ROS leaking from the matrix to activate PKG locally in that domain, before the entire cytosolic compartment becomes oxidized $(33,39)$. An alternative possibility is that an intermediary signaling molecule translocates from the mitochondria to the cytosol to activate PKG.

Interestingly, MnSOD overexpression failed to abrogate the hyperoxia-induced mitochondrial roGFP response. Because roGFP is oxidized by $\mathrm{H}_{2} \mathrm{O}_{2}$ and $\mathrm{MnSOD}$ decreases the lifetime of superoxide but may indirectly increase the level of $\mathrm{H}_{2} \mathrm{O}_{2}$ present in the matrix, the effect on the roGFP response is not surprising. However, MnSOD also failed to abolish the activation of PDE5 in hyperoxia, indicating that mitochondrial matrix superoxide is not a critical intermediary. Interestingly, MnSOD overexpression decreased the cGMP response to NO, suggesting that it can contribute to the downstream effects of increased mitochondrial $\mathrm{H}_{2} \mathrm{O}_{2}$. Overexpression of mitocatalase blocked roGFP oxidation and PDE5 activation, indicating that $\mathrm{H}_{2} \mathrm{O}_{2}$ is required for both responses. Finally, the nonspecific mitochondrially targeted antioxidant MitoTEMPO also blocked hyperoxia-induced PDE5 activity. Thus, our data are consistent with previous studies showing that exogenous $\mathrm{H}_{2} \mathrm{O}_{2}$ is capable of activating PDE5 in FPASMC (6). Regardless of the source, $\mathrm{H}_{2} \mathrm{O}_{2}$ can inhibit eNOS (15), down-regulate sGC (38), and stimulate PDE5 (6) in the pulmonary vasculature.

We also demonstrate that brief exposure to hyperoxia increases PDE5 in small PA from adult mice. These in vivo data prove that our findings are relevant across species and developmental stages. Thus, while our research has been previously focused on the neonate, these new data may suggest that hyperoxic exposures may have detrimental effects on adults as well.

In conclusion, we propose a model in which hyperoxia induces mitochondrial matrix generation of $\mathrm{H}_{2} \mathrm{O}_{2}$, which diffuses from the mitochondria to rapidly activate PKGI $\alpha$ which resides in close proximity to the mitochondria. PKGI $\alpha$ phosphorylates and increases PDE5 activity, which in turn blunts the cGMP response to exogenous NO (Fig. 10). In view of the potential toxicity associated with hyperoxic therapy, the newest guidelines for neonatal resuscitation now suggest that oxygen be titrated to meet the patient's needs (14). However, it is not yet known whether these new guidelines will avoid the cellular dysfunction associated with hyperoxia, given that these events are triggered by such brief hyperoxic exposures.

\section{Materials and Methods}

\section{Cell culture}

Primary PASMC cultures were prepared from intrapulmonary arteries isolated from healthy 136-day 
gestation fetal lambs and maintained in culture as described in the online Supplementary Data (6). PASMC were exposed to hyperoxia in a sealed humidified chamber in $95 \% \mathrm{O}_{2} / 5 \%$ $\mathrm{CO}_{2}$ (ProOx C-21, Biospherix, Lacona, NY) for $30 \mathrm{~min}$ followed by $30 \mathrm{~min}$ of recovery at $21 \% \mathrm{O}_{2} / 5 \% \mathrm{CO}_{2}$. Some cells were treated with DETANONOate $(100 \mu \mathrm{M}$; Cayman Chemical, Ann Arbor, MI), sildenafil (100 nM; provided by Drs. Francis and Corbin), MitoTEMPO (25 nM; Enzo Life Sciences, Plymouth Meeting, PA), and/or DT-3 (15 $\mu \mathrm{M}$, Calbiochem, Philadelphia, PA). Other cells were infected with an adenoviral construct expressing MnSOD (100 plaqueforming units [pfu]/cell; ViraQuest, North Liberty, IA) or mito-catalase (750 pfu/cell; University of Iowa, Iowa City, IA) or empty adenoviral vector, Y5 (100 or $750 \mathrm{pfu} / \mathrm{cell}$; University of Iowa).

\section{Hyperoxia exposure of mice and isolation of lungs and small $P A$}

The study was approved by the Northwestern University Laboratory Animal Care Committee. Male C57Bl6 mice (Charles River, age 5-6 weeks) were placed into three experimental groups: 1 ) room air, nonventilated $(21 \mathrm{NV}, n=5)$, 2) mechanically ventilation with $100 \% \mathrm{O}_{2}$ and a TOPO Dual Mode Ventilator (Kent Scientific, Torrington, CT) for $45 \mathrm{~min}$ $(100 \mathrm{~V}, n=5)$, and 3) $90 \% \mathrm{O}_{2}$ exposure for $45 \mathrm{~min}$ in an animal hyperoxia chamber (Biospherix; 90NV, $n=5$ ). After exposure, animals were euthanized, and lung tissue or PA protein was isolated as described in the online Supplementary Data (34).

\section{Western blot analysis}

FPASMC protein was harvested, and Western blot was performed as described in the online Supplementary Data (6). Membranes were blocked and incubated overnight with primary antibody at an appropriate dilution (1:333 for mouse antiPDE5 [BD Transduction], 1:500 for rabbit anti-PhosphoPDE5 [Fabgennix, Frisco, TX], and 1:2000 for mouse $\beta$-actin [Sigma, St. Louis, MO]). The membranes were incubated with the appropriate secondary antibody conjugated to horseradish peroxidase (Pierce, Rockford, IL). Membranes were exposed via chemiluminescence (Pierce) using a Digital Science Image Station (Kodak, Rochester, NY). PDE5 expression was normalized to $\beta$-actin. Data are shown as fold relative to untreated control PASMC.

\section{PDE5 activity assay}

FPASMC and small PA were harvested for total protein and assayed the same day as described in the online Supplementary Data using a commercially available colorimetric cyclic nucleotide phosphodiesterase assay kit (Enzo Life Sciences) $(6,7)$. Each sample was read with or without sildenafil $(100 \mathrm{nM})$. The difference between the picomoles of cGMP hydrolyzed per milligrams of total protein per minute with or without sildenafil represents the PDE5-specific cGMP-hydrolytic activity.

\section{cGMP enzyme immunoassay}

FPASMC and lung cGMP content was measured by enzyme immunoassay in duplicate using a commercially available kit (Cayman Chemical) as previously described (6, 7). Results are shown as picomoles of cGMP per milligram of protein for FPASMC samples and picomoles of cGMP per milligram of tissue for lung samples.

\section{Detection of ROS}

FPASMC were plated and exposed to $95 \% \mathrm{O}_{2} / 5 \% \mathrm{CO}_{2}$ for $30 \mathrm{~min}$. Immediately after exposure, FPASMC were lysed, and intracellular $\mathrm{H}_{2} \mathrm{O}_{2}$ was measured via Amplex Red assay as described in the online Supplementary Data (Invitrogen, Grand Island, NY). Other FPASMC were loaded with MitoSOX (Invitrogen), a fluorescent mitochondrially targeted superoxide probe, prior to hyperoxia exposure. MitoSOX fluorescence was measured by fluorescence microscopy with Metamorph imaging software (Molecular Devices, Sunnyvale, CA) as described in the online Supplementary Data.

FPASMC were plated on collagen-coated coverslips and infected with $100 \mathrm{pfu} / \mathrm{cell}$ of cytosolic roGFP or mitochondrial matrix-targeted roGFP (mito-roGFP) adenoviral construct. RoGFP is a previously characterized ratiometric fluorescent probe with surface-exposed cysteine residues capable of forming disulfide bonds. Assessment of fluorescence ratios provides real-time measurements of cysteine thiol redox status in that subcellular compartment $(6,9,11$, 36). After infection ( $48 \mathrm{~h}$ ), coverslips were mounted in a flowthrough chamber and perfused with a balanced salt solution bubbled with $21 \% \mathrm{O}_{2} / 5 \% \mathrm{CO}_{2}$ for fluorescent imaging on an epifluorescence inverted microscope (Nikon, Japan) with a cooled CCD camera (Photometrics, Tucson, AZ) connected to a computer running Metafluor (Universal Imaging, Downington, PA) as previously described (36). The roGFP probe was excited using 400 and $485 \mathrm{~nm}$, and emission at $525 \mathrm{~nm}$ was imaged. After establishing a stable baseline, the gas perfusion mixture was changed to $95 \% \mathrm{O}_{2} / 5 \% \mathrm{CO}_{2}$ for $30 \mathrm{~min}$. After $30 \mathrm{~min}$, the cells were returned to $21 \% \mathrm{O}_{2} / 5 \%$ $\mathrm{CO}_{2}$ for $30 \mathrm{~min}$. For calibration, the probe was fully reduced with dithiothreitol ( $1 \mathrm{mM}$, Sigma) and fully oxidized using tbutyl hydroperoxide ( $1 \mathrm{mM}$, Sigma). For each pair of images, a ratiometric image was obtained ( $485 \mathrm{~nm}$ divided by $400 \mathrm{~nm}$ image). For each condition, the cysteine thiol redox status was calculated as percent oxidized, by comparison to the values obtained for the fully reduced and fully oxidized conditions.

\section{Statistical analysis}

All data are expressed as mean \pm SEM. Results were analyzed by unpaired $t$-test or ANOVA with Bonferroni's post hoc analysis when appropriate using Prism software (GraphPad Software Inc., San Diego, CA). Statistical significance was set at $p<0.05$.

\section{Acknowledgments}

The authors thank Sharron Francis and Jackie Corbin, Vanderbilt University, for providing sildenafil, and Sylvia Gugino and Lyubov Czech for expert technical assistance. This work was supported by Northwestern University Alumnae Grant (K.N.F.), Neonatal Resuscitation Program Young Investigator Grant (K.N.F.), and National Institutes of Health grants: HL086715 and HL109478 (K.N.F.), HL054705 (R.H.S.), and HL035440 and HL079650 (P.T.S.). 


\section{Author Disclosure Statement}

No competing financial interests exist.

\section{References}

1. Part 13: Neonatal Resuscitation Guidelines. Circulation 112: IV188-IV195, 2005.

2. Abman SH, Chatfield BA, Hall SL, and McMurtry IF. Role of endothelium-derived relaxing factor during transition of pulmonary circulation at birth. Am J Physiol 259: H1921H1927, 1990.

3. Bloch KD, Filippov G, Sanchez LS, Nakane M, and de la Monte SM. Pulmonary soluble guanylate cyclase, a nitric oxide receptor, is increased during the perinatal period. Am J Physiol 272: L400-L406, 1997.

4. Burgoyne JR, Madhani M, Cuello F, Charles RL, Brennan JP, Schroder E, Browning DD, and Eaton P. Cysteine redox sensor in PKGIa enables oxidant-induced activation. Science 317: 1393-1397, 2007.

5. Dikalova AE, Bikineyeva AT, Budzyn K, Nazarewicz RR, McCann L, Lewis W, Harrison DG, and Dikalov SI. Therapeutic targeting of mitochondrial superoxide in hypertension. Circ Res 107: 106-116, 2010.

6. Farrow KN, Groh BS, Schumacker PT, Lakshminrusimha S, Czech L, Gugino SF, Russell JA, and Steinhorn RH. Hyperoxia increases phosphodiesterase 5 expression and activity in ovine fetal pulmonary artery smooth muscle cells. Circ Res 102: 226-233, 2008.

7. Farrow KN, Lakshminrusimha S, Czech L, Groh BS, Gugino SF, Davis JM, Russell JA, and Steinhorn RH. Superoxide dismutase and inhaled nitric oxide normalize phosphodiesterase 5 expression and activity in neonatal lambs with persistent pulmonary hypertension. Am J Physiol Lung Cell Mol Physiol 299: L109-116, 2010.

8. Farrow KN, Lakshminrusimha S, Reda WJ, Wedgwood S, Czech L, Gugino SF, Davis JM, Russell JA, and Steinhorn $\mathrm{RH}$. Superoxide dismutase restores eNOS expression and function in resistance pulmonary arteries from neonatal lambs with persistent pulmonary hypertension. Am J Physiol Lung Cell Mol Physiol 295: L979-987, 2008.

9. Farrow KN, Wedgwood S, Lee KJ, Czech L, Gugino SF, Lakshminrusimha S, Schumacker PT, and Steinhorn RH. Mitochondrial oxidant stress increases PDE5 activity in persistent pulmonary hypertension of the newborn. Respir Physiol Neurobiol 174: 272-281, 2010.

10. Fernandes MA, Marques RJ, Vicente JA, Santos MS, Monteiro P, Moreno AJ, and Custodio JB. Sildenafil citrate concentrations not affecting oxidative phosphorylation depress $\mathrm{H} 2 \mathrm{O} 2$ generation by rat heart mitochondria. Mol Cell Biochem 309: 77-85, 2008.

11. Hanson GT, Aggeler R, Oglesbee D, Cannon M, Capaldi RA, Tsien RY, and Remington SJ. Investigating mitochondrial redox potential with redox-sensitive green fluorescent protein indicators. J Biol Chem 279: 13044-13053, 2004.

12. Hanson KA, Burns F, Rybalkin SD, Miller JW, Beavo J, and Clarke WR. Developmental changes in lung cGMP phosphodiesterase- 5 activity, protein, and message. Am J Respir Crit Care Med 158: 279-288, 1998.

13. Hemnes AR, Zaiman A, and Champion HC. PDE5A inhibition attenuates bleomycin-induced pulmonary fibrosis and pulmonary hypertension through inhibition of ROS generation and RhoA/Rho kinase activation. Am J Physiol Lung Cell Mol Physiol 294: L24-33, 2008.
14. Kattwinkel J, Perlman JM, Aziz K, Colby C, Fairchild K, Gallagher J, Hazinski MF, Halamek LP, Kumar P, Little G, McGowan JE, Nightengale B, Ramirez MM, Ringer S, Simon WM, Weiner GM, Wyckoff M, and Zaichkin J. Neonatal resuscitation: 2010 American Heart Association guidelines for cardiopulmonary resuscitation and emergency cardiovascular care. Pediatrics 126: e1400-1413, 2010.

15. Kumar S, Sun X, Wedgwood S, and Black SM. Hydrogen peroxide decreases endothelial nitric oxide synthase promoter activity through the inhibition of AP-1 activity. Am J Physiol Lung Cell Mol Physiol 295: L370-377, 2008.

16. Lakshminrusimha S, Russell JA, Steinhorn RH, Ryan RM, Gugino SF, Morin FC 3rd, Swartz DD, and Kumar VH. Pulmonary arterial contractility in neonatal lambs increases with 100\% oxygen resuscitation. Pediatr Res 59: 137-141, 2006.

17. Lakshminrusimha S, Russell JA, Steinhorn RH, Swartz DD, Ryan RM, Gugino SF, Wynn KA, Kumar VH, Mathew B, Kirmani K, and Morin FC 3rd. Pulmonary hemodynamics in neonatal lambs resuscitated with $21 \%, 50 \%$, and $100 \%$ oxygen. Pediatr Res 62: 313-318, 2007.

18. Lakshminrusimha S, Russell JA, Wedgwood S, Gugino SF, Kazzaz JA, Davis JM, and Steinhorn RH. Superoxide dismutase improves oxygenation and reduces oxidation in neonatal pulmonary hypertension. Am J Respir Crit Care Med 174: 1370-1377, 2006.

19. Lakshminrusimha S, Swartz DD, Gugino SF, Ma C-X, Wynn KA, Ryan RM, Russell JA, and Steinhorn RH. Oxygen concentration and pulmonary hemodynamics in newborn lambs with pulmonary hypertension. Pediatr Res 66: 539$544,2009$.

20. Lu Z, Xu X, Hu X, Lee S, Traverse JH, Zhu G, Fassett J, Tao Y, Zhang P, dos Remedios C, Pritzker M, Hall JL, Garry DJ, and Chen Y. Oxidative stress regulates left ventricular PDE5 expression in the failing heart. Circulation 121: 1474-1483, 2010.

21. Milara J, Juan G, Ortiz JL, Guijarro R, Losada M, Serrano A, Morcillo EJ, and Cortijo J. Cigarette smoke-induced pulmonary endothelial dysfunction is partially suppressed by sildenafil. Eur J Pharm Sci 39: 363-372, 2010.

22. Murthy KS. Activation of phosphodiesterase 5 and inhibition of guanylate cyclase by cGMP-dependent protein kinase in smooth muscle. Biochem J 360: 199-208, 2001.

23. Muzaffar S, Shukla N, Bond M, Sala-Newby GB, Newby AC, Angelini GD, and Jeremy JY. Superoxide from NADPH oxidase upregulates type 5 phosphodiesterase in human vascular smooth muscle cells: inhibition with iloprost and NONOate. Br J Pharmacol 155: 847-856, 2008.

24. O'Reilly MA, Marr SH, Yee M, McGrath-Morrow SA, and Lawrence BP. Neonatal hyperoxia enhances the inflammatory response in adult mice infected with influenza A virus. Am J Respir Crit Care Med 177: 1103-1110, 2008.

25. Rybalkin SD, Rybalkina IG, Feil R, Hofmann F, and Beavo JA. Regulation of cGMP-specific phosphodiesterase (PDE5) phosphorylation in smooth muscle cells. J Biol Chem 277: 3310-3317, 2002.

26. Sander F, Gao Y, and Raj JU. Hypoxia down-regulates cyclic guanidine monophosphate-dependent protein kinase in fetal pulmonary vascular smooth muscle cell through generation of reactive oxygen species and promotes development of pulmonary hypertension. Chest 128: 577S-578S, 2005.

27. Saugstad OD, Ramji S, and Vento M. Resuscitation of depressed newborn infants with ambient air or pure oxygen: a meta-analysis. Biol Neonate 87: 27-34, 2005.

28. Saugstad OD, Rootwelt $\mathrm{T}$, and Aalen O. Resuscitation of asphyxiated newborn infants with room air or oxygen: an 
international controlled trial: the Resair 2 study. Pediatrics 102: e1, 1998.

29. Schermuly RT, Pullamsetti SS, Kwapiszewska G, Dumitrascu R, Tian X, Weissmann N, Ghofrani HA, Kaulen C, Dunkern T, Schudt C, Voswinckel R, Zhou J, Samidurai A, Klepetko W, Paddenberg R, Kummer W, Seeger W, and Grimminger F. Phosphodiesterase 1 upregulation in pulmonary arterial hypertension: target for reverse-remodeling therapy. Circulation 115: 2331-2339, 2007.

30. Schulz E, Tsilimingas N, Rinze R, Reiter B, Wendt M, Oelze M, Woelken-Weckmuller S, Walter U, Reichenspurner $\mathrm{H}$, Meinertz T, and Munzel T. Functional and biochemical analysis of endothelial (dys)function and NO/cGMP signaling in human blood vessels with and without nitroglycerin pretreatment. Circulation 105: 1170-1175, 2002.

31. Vandeput F, Krall J, Ockaili R, Salloum FN, Florio V, Corbin JD, Francis SH, Kukreja RC, and Movsesian MA. cGMPhydrolytic activity and its inhibition by sildenafil in normal and failing human and mouse myocardium. J Pharmacol Exp Ther 330: 884-891, 2009.

32. Vento M, Asensi M, Sastre J, Garcia-Sala F, Pallardo FV, and Vina J. Resuscitation with room air instead of $100 \%$ oxygen prevents oxidative stress in moderately asphyxiated term neonates. Pediatrics 107: 642-647, 2001.

33. Vitiello PF, Wu YC, Staversky RJ, and O'Reilly MA. p21(Cip1) protects against oxidative stress by suppressing ER-dependent activation of mitochondrial death pathways. Free Radic Biol Med 46: 33-41, 2009.

34. Waypa GB, Chandel NS, and Schumacker PT. Model for hypoxic pulmonary vasoconstriction involving mitochondrial oxygen sensing. Circ Res 88: 1259-1266, 2001.

35. Waypa GB, Guzy R, Mungai PT, Mack MM, Marks JD, Roe MW, and Schumacker PT. Increases in mitochondrial reactive oxygen species trigger hypoxia-induced calcium responses in pulmonary artery smooth muscle cells. Circ Res 99: 970-978, 2006.

36. Waypa GB, Marks JD, Guzy R, Mungai PT, Schriewer J, Dokic D, and Schumacker PT. Hypoxia triggers subcellular compartmental redox signaling in vascular smooth muscle cells. Circ Res 106: 526-535, 2010.

37. Wedgwood S, Lakshminrusimha S, Fukai T, Russell JA, Schumacker PT, and Steinhorn RH. Hydrogen peroxide regulates extracellular superoxide dismutase activity and expression in neonatal pulmonary hypertension. Antioxid Redox Signal 15: 1497-1506, 2011.

38. Wedgwood S, Steinhorn RH, Bunderson M, Wilham J, Lakshminrusimha S, Brennan LA, and Black SM. Increased hydrogen peroxide downregulates soluble guanylate cyclase in the lungs of lambs with persistent pulmonary hypertension of the newborn. Am J Physiol Lung Cell Mol Physiol 289: L660-666, 2005.
39. Wilson LS, Elbatarny HS, Crawley SW, Bennett BM, and Maurice DH. Compartmentation and compartment-specific regulation of PDE5 by protein kinase $G$ allows selective cGMP-mediated regulation of platelet functions. Proc Natl Acad Sci USA 105: 13650-13655, 2008.

40. Yee M, White RJ, Awad HA, Bates WA, McGrath-Morrow SA, and O'Reilly MA. Neonatal hyperoxia causes pulmonary vascular disease and shortens life span in aging mice. Am J Pathol 178: 2601-2610, 2011.

Address correspondence to: Dr. Kathryn N. Farrow Department of Pediatrics Northwestern University Feinberg School of Medicine 310 E. Superior Street, Morton 4-685

Chicago, IL 60611

E-mail: k-farrow@northwestern.edu

Date of first submission to ARS Central, July 22, 2011; date of final revised submission, January 5, 2012; date of acceptance, January 7, 2012.

\begin{tabular}{|c|}
\hline 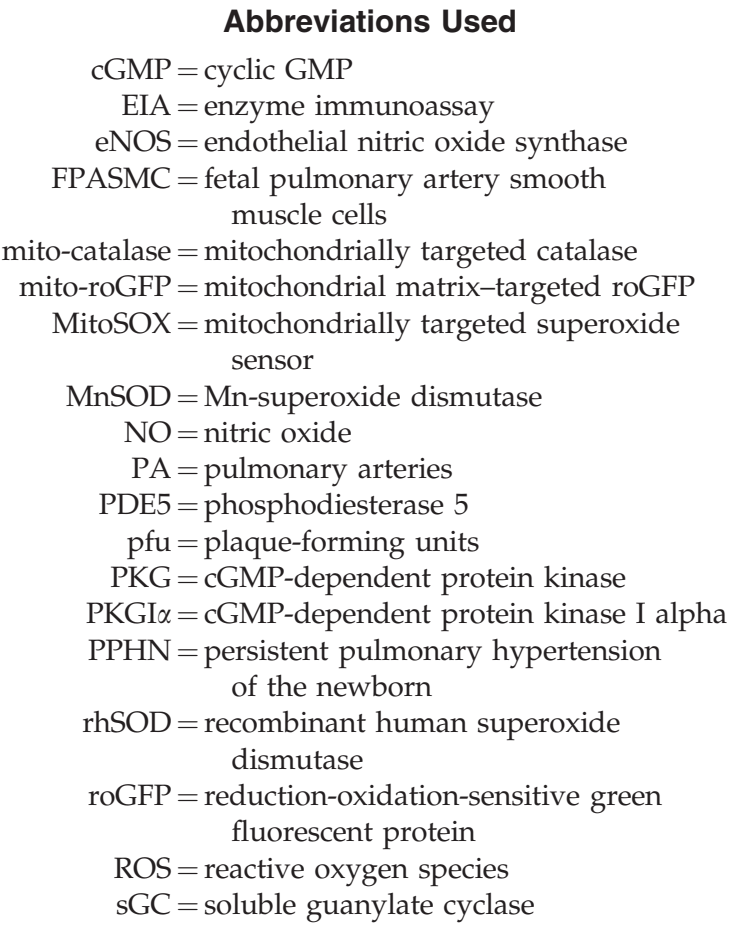 \\
\hline
\end{tabular}

